Review

\title{
TLC-Direct Bioautography as a High Throughput Method for Detection of Antimicrobials in Plants
}

\author{
Irena M. Choma * and Wioleta Jesionek * \\ Department of Chromatographic Methods, Maria Curie-Skłodowska University, \\ Maria Curie-Skłodowska Sq. 3, 20-031 Lublin, Poland \\ * Authors to whom correspondence should be addressed; E-Mails: irena.choma@umcs.lublin.pl (I.M.C.); \\ wioleta.jesionek@o2.pl (W.J.); Tel.: +48-815375698.
}

Academic Editor: Mark Devlin Maloney

Received: 3 March 2015 / Accepted: 12 May 2015 / Published: 18 May 2015

\begin{abstract}
The richness of bioactive compounds in plant materials encourages continuous development of separation methods and bioassays for their isolation and identification. Thin-layer chromatography-direct bioautography links separation on the adsorbent layer with biological tests performed directly on it. Therefore, the method is very convenient for searching plant constituents with biological activity, such as antibiotics. Test bacteria grow directly on a plate surface excluding places where antibacterials are located. They can be detected with reagents converted by living bacteria. TLC-DB is a high throughput method enabling analyses of many samples in parallel and the comparison of their activity. Both screening and semi-quantitative analysis is possible. The targeted compounds can be identified using spectroscopic methods, mostly mass spectrometry, that can be performed directly on a TLC plate. This paper discusses all above mentioned aspects of TLC-DB, illustrating them with literature, schemes and our own results.
\end{abstract}

Keywords: thin-layer chromatography-direct bioautography; effect-directed analysis, antimicrobials; biological screening

\section{Introduction}

The world of plants constitutes an almost unlimited source of biologically active substances which are or could be used in the treatment of many human, animal and plant diseases [1,2]. The biggest efforts are concentrated on finding cures for civilization's ills, such as cardiovascular problems, 
diabetes, Alzheimer's and other degenerative diseases, as well as for cancer. Moreover, mankind urgently needs new antibiotics to fight bacterial diseases such as tuberculosis, pneumonia, gastroenteritis, meningitis and sepsis. Though it sounds improbable, almost one century after the discovery of penicillin, many known and powerful antibiotics are no longer effective against these and other infections. The situation is mostly related to increasing bacterial resistance against commonly used antibiotics [3-5].

Chromatography is a perfect tool for analyzing plant constituents. High-performance liquid chromatography (HPLC) gives the biggest separation possibilities and additionally can provide information on the structures of separated compounds (HPLC-DAD, HPLC-MS). However, it is difficult to link this information with the information on biological (e.g., antibacterial) properties. This problem can be solved by effect-directed analysis (EDA) which provides information on biologically relevant substances even in very complex matrices, such as plant tissue extracts [6]. The best results can be achieved when EDA connects bio- or toxicity-assays with instrumental analysis [7-9]. The ideal chromatographic method for this type of connection is thin-layer chromatography (TLC). TLC linked to biological assay (e.g., antimicrobial or enzymatic) or to chemical detection indicating biological properties (e.g., TLC-DPPH for testing radical scavenging properties) is generally call TLC-bioautography (TLC-B). Thin-layer chromatography-direct bioautography (TLC-DB) is one of three variants of a TLC-B method (the others are contact and agar overlay bioautography) in which separation, a given assay and visualization are performed directly on a TLC layer. Mostly, this is used for testing antimicrobial properties directly on a TLC plate covered with a thin layer of bacteria or fungi, as opposed to a thick layer of inoculated agar in agar overlay bioautography [6,10,11]. TLC seems to be an ideal method for hyphenation with bioautographic detection because of an open layer enabling solvent evaporation, and the possibility of separating many samples in parallel. Besides classical TLC, high-performance thin-layer chromatography (HPTLC), overpressured-layer chromatography (OPLC) and planar electro-chromatography (PEC) can also be easily linked to bioautography [12-18].

\section{TLC-DB (Thin-Layer Chromatography-Direct Bioautography)}

In TLC-DB of antimicrobials, a developed TLC plate is dipped in a suspension of microorganisms growing in a nutrient broth, and then incubated in a humid atmosphere. The microorganisms grow directly on the surface of a TLC plate excluding spots of antimicrobials. Visualization is usually carried out by spraying a plate with tetrazolium salt such as MTT (3-(4,5-dimethylthiazol-2-yl)-2,5diphenyltetrazolium bromide). The dehydrogenases of living microorganisms convert tetrazolium salt into a purple formazan [10,11]. Creamy spots appearing against a purple background, so-called inhibition zones, point to the presence of antimicrobial agents. The most frequently used test bacteria are Gram-positive, Bacillus subtilis, and Gram-negative, Escherichia coli. The tests based on these bacteria were fully validated in our laboratory and used for screening antibiotics in milk [19-22]. Recently, we have also started to use them in plant analysis [13,14,23]. Antibacterial properties of plant constituents were checked against Staphylococcus aureus, methicillin-resistant Staphylococcus aureus, Staphylococcus epidermidis, Xanthomonas campestris pv. vesicatoria, and Micrococcus luteus [24-27]. In the literature, there are also a few examples of TLC-DB based on Staphylococcus saprophyticus, Bacillus cereus, Pseudomonas syringae pv. phaseolicola and Micrococcus lysodeikticus [24-26,28]. 
TLC can be also hyphenated with bioluminescence detection using mostly Aliivibrio fischeri, (previous name Vibrio fisheri) and Photobacterium phosphoreum luminescent bacteria. Antibacterials and other compounds toxic to bacteria (mycotoxines, pesticides, heavy metals) disturb the metabolism of these bacteria, which in turns causes quenching of their luminescence. TLC-DB bioluminescent test is performed in a similar way as described above for non-luminescent bacteria. The developed TLC plate is immersed in a bacterial broth inoculated with luminescent bacteria and almost immediately observed at $490 \mathrm{~nm}$ under cooled CCD camera. The changes in emission of blue-green light (darker or brighter zones), related to disturbance in vital cell processes, indicate the presence of toxic substances [12,15,24,29,30] (Figure 1). The image conversion and spreadsheet programs enable data interpretation [31]. Another luminescent test, using a genetically modified plant, pathogenic bacterium Pseudomonas syringae pv. maculicola, was applied in searching for natural agents against bacterial plant infections [18,29,32]. It is worth mentioning that the commercial Aliivibio fischeri test-Bioluminex ${ }^{\mathrm{TM}}-$ is available on the market [33]. Unfortunately, there are no such tests available for other, non-luminescent bacteria.

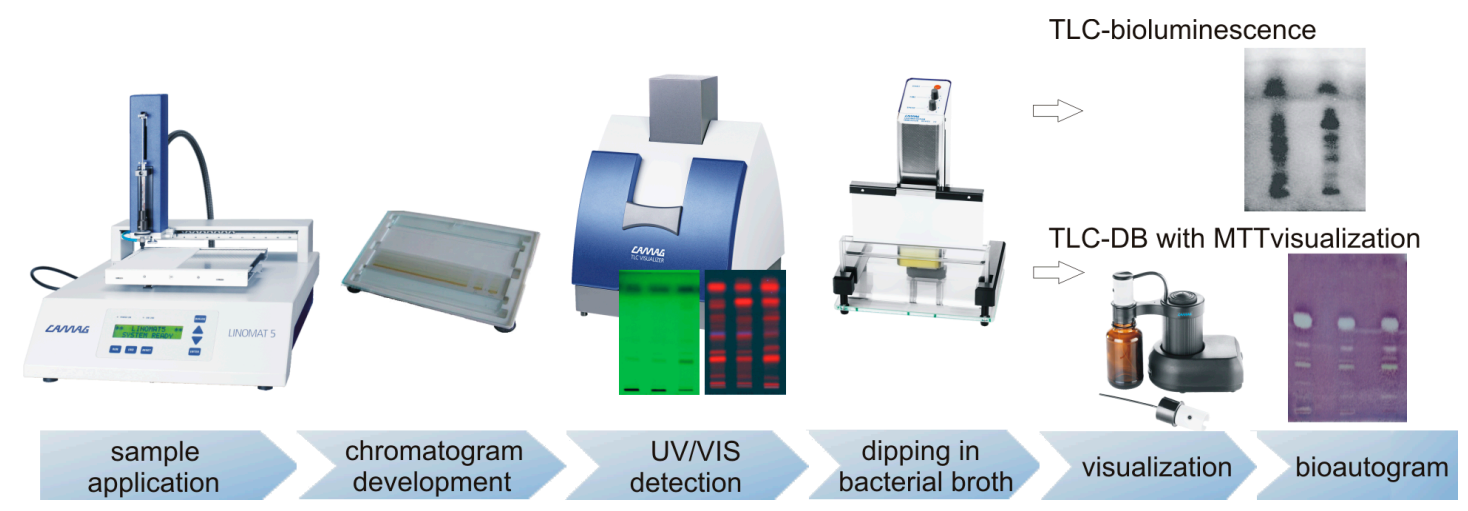

Figure 1. The general scheme of TLC-DB procedure. This equipment was reproduced with permission from Camag.

\subsection{TLC-DB-“dot-blot” Test}

In a dot-blot direct bioautography, compounds to be detected are not separated on a TLC plate. Instead, a mixture containing the targeted compounds is applied directly on a plate, and after solvent evaporation, the plate is immersed in a bacterial broth. The other steps are as in classical TLC-DB. The assay was successfully used to performed preliminary experiments on antibacterial activity of chosen plant ethanol extracts (here against Staphylococcus aureus). The differences between activities of individual extracts were clearly visible. The test also allowed exlusion of activity of ethanol used for the extraction process - the blank sample (Figure 2). Dot-blot TLC-DB allows simplification and timesaving but on the other hand produces only preliminary results. The components of a mixture can have synergistic or antagonistic effects, masking properties of single compounds. Still, the test can indicate if a given sample, e.g., plant extract, is worth further investigation [14,21,24,34]. The bioautographic dot-blot can be also advised if pure compounds are analyzed. Then, the method can be used even for semi-quantitative measurements. Calibration curves can be constructed for standards and be used to estimate the amount of analyte in real samples. The method was applied, for instance, to measure the concentration of cefacetril in milk samples collected from cows after intra-mammary administration of the antibiotic. The results were very similar to those obtained in parallel by HPLC [35]. It should be 
mentioned here that calibration curves in TLC-DB (also dot-blot) are constructed as dependency between inhibition zone areas and logarithm of concentration/amount of analyzed substance. They are linear for narrow range of concentration (up to two orders of magnitude) but exponential for the wider range. Because the inhibition zone area depends on the volume of the sample it is very important to apply standards and the targeted samples at the same volume [36].

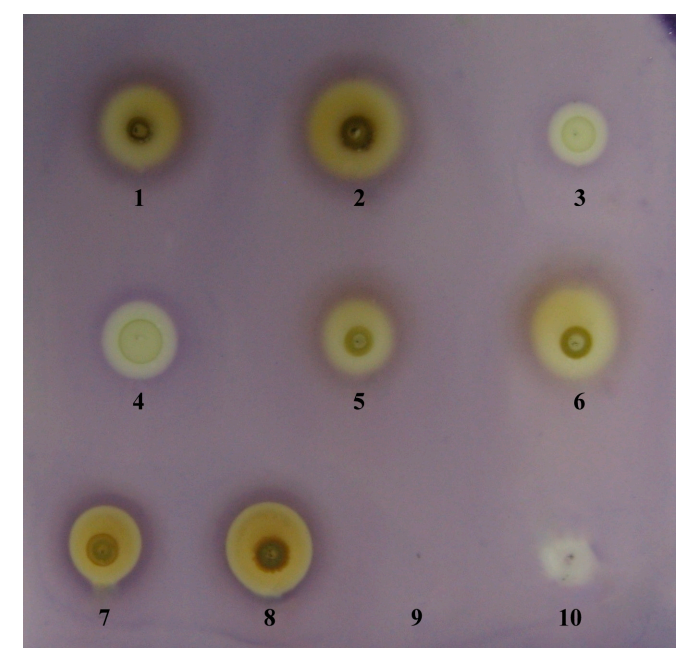

Figure 2. TLC-DB dot-blot test of plant tinctures. Thymus vulgaris $\mathrm{L}$. $5 \mu \mathrm{L}-1,10 \mu \mathrm{L}-2$; Mentha $x$ piperita L. $5 \mu \mathrm{L}-3,10 \mu \mathrm{L}-4$; Salvia officinalis L. $5 \mu \mathrm{L}-5,10 \mu \mathrm{L}-6$; Hypericum perforatum L. $5 \mu \mathrm{L}-7,10 \mu \mathrm{L}-8$; ethanol $70 \% 10 \mu \mathrm{L}-9$; genthamycin $(\mathrm{c}=40 \mathrm{mg} / \mathrm{mL}) 5 \mu \mathrm{L}-$ 10. Detection against $S$. aureus.

\subsection{TLC-DB-Developed Plates}

In case of very complex matrices, like plant extracts, biological screening performed on developed TLC plates is a very convenient way to obtain reliable information on the activity of single compounds. There is no doubt that optimized antimicrobial assays (TLC-DB, TLC-bioluminescence) are useful tools both for the analytical determination of main compounds of plant extracts and for characterization of their biological properties (Figure 3). The investigation of the separated components gives far more precise information than that obtained from popular microbiological dilution or diffusion tests (e.g., agar disc diffusion) [19,20] or TLC-DB dot-blot, in which unseparated crude extracts are evaluated. As was already mentioned, components of a crude extract can affect each other, and biological activities of individual compounds can be masked, which can be avoided through TLC separation of sample components. TLC-DB dot-blot test of thyme ethanol extract pointed to its antibacterial properties in general (Figure 2) while its separation reveals several active constituents (Figure 3). Antibacterial properties are not only attributed to essential oil components, like thymol, carvacrol or linalool, but also to more polar compounds seen below on the TLC plate. This simple example is only one from many others described in the literature proving that TLC-DB is an effective time- and money-saving tool for bioassay-guided detection of antibacterial components [18,24,29].

Sometimes subsequent separations are necessary to eliminate fractions with no biological response. It is especially advisable in the case of active zones near the origin, which should be separated once more with more polar mobile phase to reveal active sub-fractions and to reject non-active ones. 
Usually, to obtain bigger amounts of fractions with antibacterial activity, semi-preparative chromatography is used. Then, the targeted fractions can be subjected to other measurements, for instance spectroscopic ones (see Section 3.1).

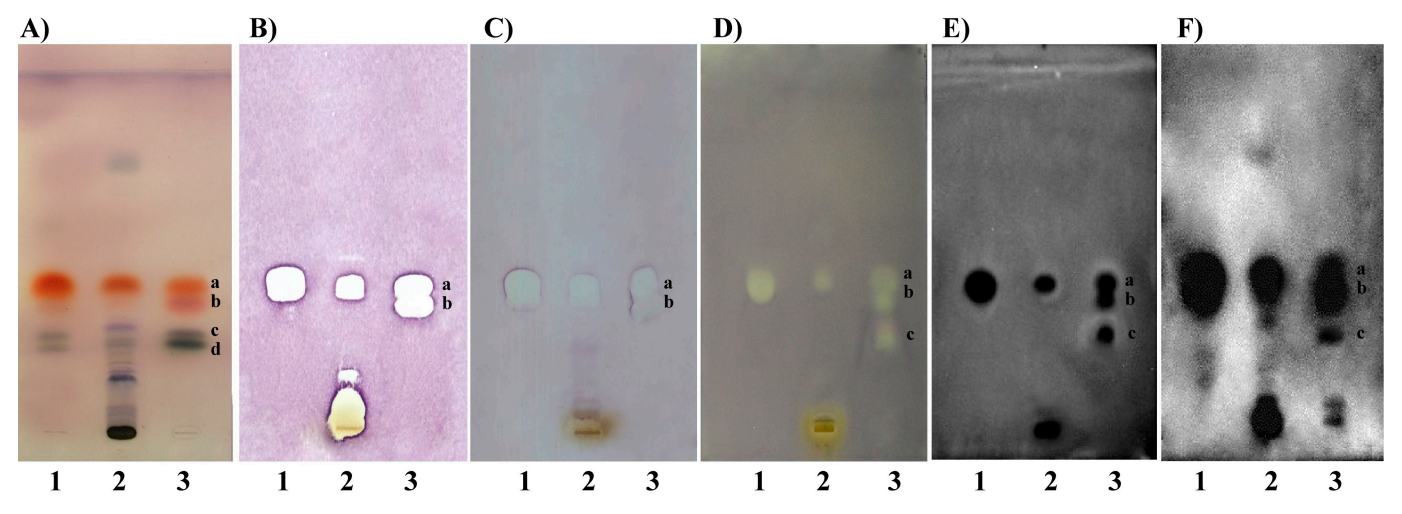

Figure 3. TLC Si60 F 254 plates: (A) derivatization with anisaldehyde-sulphuric acid reagent; TLC-DB against: (B) Bacillus subtilis, (C) Escherichia coli, (D) Xanthomonas campestis pv. vesicatoria, (E) Pseudomonas syringae pv. maculicola, (F) Aliivibrio fischerii; tracks (1) thyme essential oil, (2) thyme 70\% ethanol extract, (3) mixture of standards: a-thymol, b-carvacrol, c-linalool, d-borneol; mobile phase: chloroform.

A variation of direct bioautography was created by Tyihák and co-workers. The BioArena system enables observation of biochemical interactions between microorganisms and biologically active compounds (e.g., antibiotics, mycotoxins), occurring in the adsorbent layer covered with microorganisms. Separation is performed by the overpressured layer chromatography (OPLC). This forced flow technique uses external pressure to introduce a mobile phase into the layer. Such resolution gives better separation and more compact spots; therefore, this technique allows better resolution of the analytes on the plate than TLC. The primary objective of the BioArena method is investigation of small molecules, which are key substances for biological systems (endogenous formaldehyde, hydrogen peroxide and ozone), and their impact on the antibiotic effect of the tested substances as well as on proliferation of bacteria $[17,37,38]$.

TLC-DB is also a very effective assay in searching for natural compounds with antifungal properties. Samples are separated by TLC then sprayed with a suspension containing fungal cells and incubated under suitable conditions. Compounds exhibiting antifungal properties are visible as a light cream-colored zone on the grey background. A great majority of analyses focused on searching for antifungal agents using the TLC-DB method concern the plant extracts. The first antifungal bioautographic test based on Cladosporium cucumerinum was established by Homans and Fusch [39]. The test was later applied by Hostettmann and co-workers in searching for antifungal properties of plants such as Swertia calycina (Gentianaceae), Erythrina vogelii (Fabaceae), and Blumea gariepina (Asteraceae) [40-42]. Other frequently used microorganisms were Candida albicans, Aspergillus, and Penicillium $s p$. These experiments provided a great deal of information about natural compounds possessing antifungal properties in several species: Dictamnus dasycarpus (Rutaceae), Gentiana algida (Gentianaceae), Gentiana macrophylla (Gentianaceae), and Newbouldia laevis (Bignoniaceae). The structures of the found bioactive compounds were established by chemical and spectroscopic 
methods, mostly MS and NMR [40-46]. Another approach in searching natural fungicides is presented by Wedge and co-workers. The group use TLC-DB mostly against Colletotrichum sp. (Colletotrichum acutatum, Colletotrichum fragariae, Colletotrichum gloeosporioides) [47]. Activity of many volatile constituents in Angelica sinensis (Apiaceae), Angelica archangelica (Apiaceae), Haplopappus greenei (Asteraceae), Origanum onites (Lamiaceae), Arnica longifolia (Asteraceae), Aster hesperius (Asteraceae), Chrysothamnus nauseosus (Asteraceae) species and others were detected by TLC-bioautography followed by their identification using mostly GC-MS and GC-FID [48-51]. The hyphenation of TLC-DB with NMR enabled detection of thirteen amides presented in plants from the Piperaceae family showing strong activity against Cladosporium sphaerospermum [52].

Besides searching for bioactive compounds, TLC-DB can serve other purposes, such as finding the best solvent for extraction of active compounds from a given matrix [13,26,27,53], or selection of a mobile phase providing a suitable separation of investigated samples [14,26,27]. TLC-DB also allows comparison of bioactivity for samples of various origin in parallel (e.g., different plant species or extracts from the different parts of the plant) $[13,14,26,27,53]$.

\section{Identification of Bioactive Compounds}

TLC-DB is often used as a bio-guiding method to point to substances with biological activity that can be further analyzed by spectroscopic methods to obtain information on their structure. Usually, active components found in analytical-scale TLC-DB, should be acquired in amounts and purity sufficient for spectroscopic evaluation. The most important technique used for this purpose is preparative TLC (PLC), realized on preparative plates (layers thicker than $0.25 \mathrm{~mm}$ ), or semi-preparative TLC, performed on analytical plates.

\subsection{Preparative Sample Isolation}

Preparative or semi-preparative TLC technique can be used to obtain larger amounts of the fraction/compound of interest. The sample is applied as a wide band and developed under selected chromatographic conditions. After solvent evaporation, bands of desired bioactive compounds are scraped off together with silica gel, and then they are eluted with appropriate solvent to vials. TLC semi-preparative fractionation of compounds showing antibacterial activity was successfully performed in our laboratory for many kinds of plant samples, such as Matricaria recutita (Asteraceae), Achillea millefolium (Asteraceae), Salvia officinalis (Lamiaceae), Thymus vulgaris (Lamiaceae) Chelidonium majus (Papaveraceae) and Hypericum perforatum (Hypericaceae) [54,55]. The bioactive fractions of Hypericum perforatum visible on schematic TLC-DB bioautogram (Figure 4) were isolated using semi-preparative TLC. Then they were concentrated and subjected to LC-MS analysis for structural evaluation. Five bioactive compounds were identified: 3,8'-biapigenin, quercetin, apigenin, kaempferol and linolenic acid [54]. 


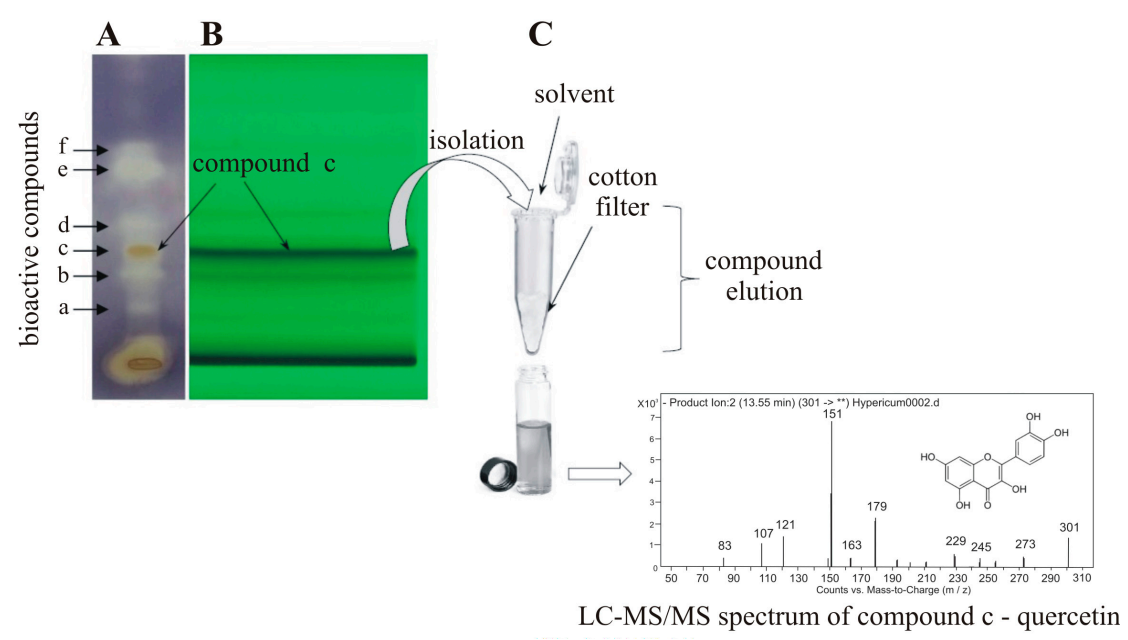

Figure 4. The general scheme of bio-guided semi-preparative TLC fractionation.

Another and more sophisticated way to obtain larger amounts of the targeted compounds from a TLC plate is the application of the OPLC system. The instrument consists of a separation chamber and a programmable liquid delivery system which provides homogenous external pressure driving the mobile phase through an adsorbent bed. OPLC equipment, working in mixed operating mode (off-line sample application and on-line detection), can be used for fractionation and isolation of separated components from different matrices including tissue extract. The OPLC enables purification of a sample directly in an adsorbent layer by washing uninteresting compounds off, using a direction opposite to that of a mobile phase. The purified components of interest remain at the start point and then are developed with a mobile phase. Detection can be achieved using flow-through UV detector coupled online with a fraction collector. The OPLC provides an efficient isolation of various substances from various matrices, including antimicrobial components, like essential oils of plants. Collected fractions can be concentrated and subjected to further experiments: TLC-DB, chemical derivatization and/or structural identification by spectroscopic methods [18,32,56-58].

A new separation technique, so-called orthogonal pressurized planar electrochromatography (OPPEC), introduced by T. Dzido and co-workers, seems to be a promising solution. This combination of OPLC and pressurized planar electrochromatography (PPEC) enables on-line application and continuous, micropreparative, orthogonal sample separation [59].

\subsection{Coupling TLC to Mass Spectrometry}

Recent trends in development of thin-layer chromatography have been focused on its hyphenation with various spectroscopic identification techniques. Undoubtedly, mass spectrometry (MS) plays a major role among other methods like infra-red (IR) or nuclear magnetic resonance (NMR). TLC-MS approaches can be divided into two groups: elution-based and desorption-based techniques [60,61]. The first group includes micro capillary arrow, surface sampling probe, overrun chromatography on a TLC strip, forced-flow techniques like OPLC and RPC (rotation planar chromatography) and elution head-based interfaces (including Camag TLC-MS Interface). The group of desorption-based approaches includes desorption by fast atom bombardment (FAB), desorption by ion bombardment (SIMS), desorption by laser light (ablation), e.g., MALDI, desorption by a spray beam, e.g., DESI [62] 
and desorption by an excited gas beam to which belongs a quite new type of a technique-direct analysis in real time (DART) [63]. Most of the listed above approaches can be described as semi-automatic or so-called off-line techniques in which development of the chromatogram and recording of mas spectra are two independent steps. However, some couplings based on an overrun chromatography or on forced-flow techniques are fully on-line [60]. A wide range of isolation devices provides new opportunities for (HP)TLC techniques. Based on the number of published articles, two types of commercially available instruments are starting to play the most important role in coupling TLC with mass spectrometry: the TLC-MS Interface (CAMAG) (working in the elution mode) and the DART system (IonSense) (working in the desorption mode) (Figure 5).

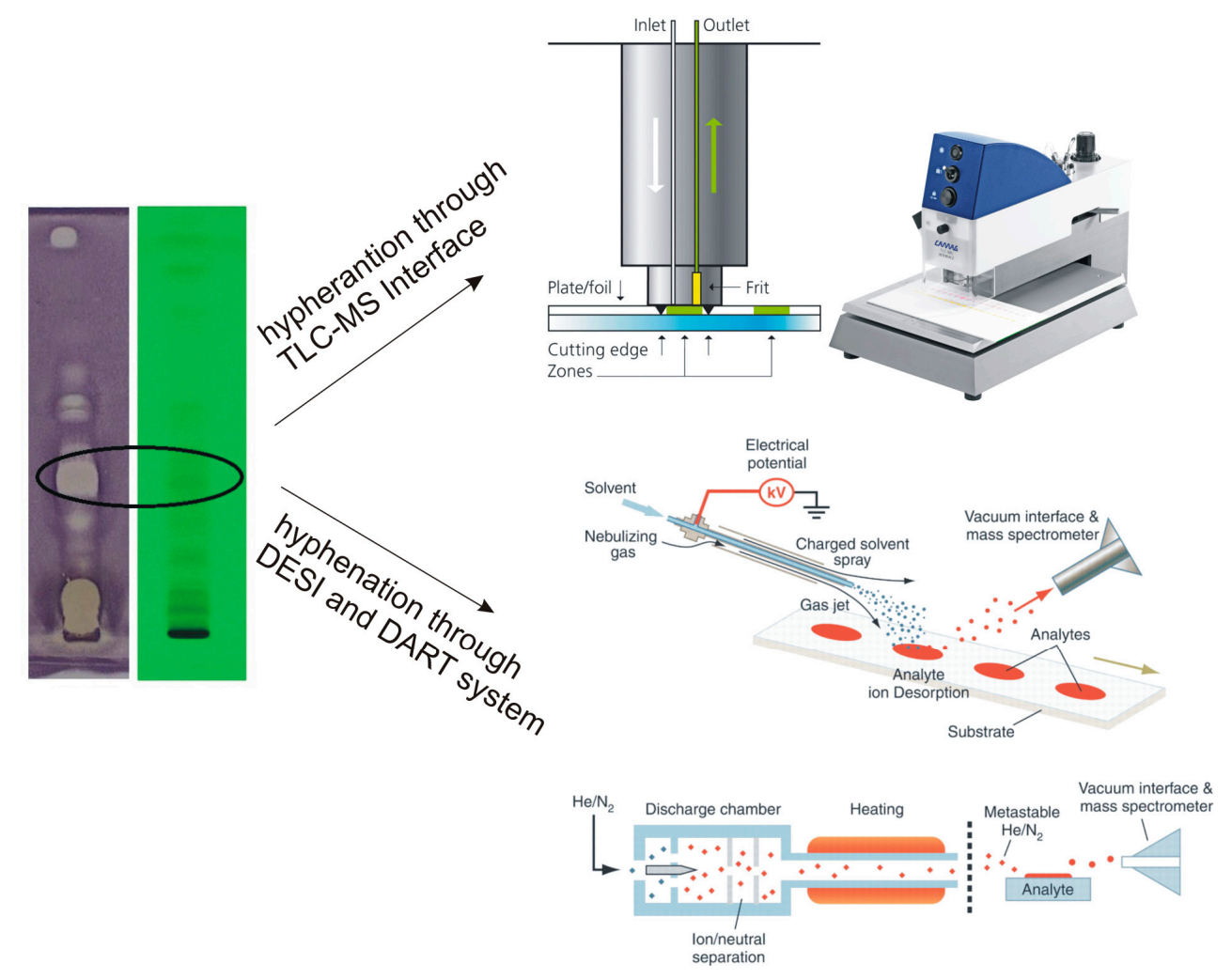

Figure 5. The scheme illustrating TLC-MS Interface, TLC-DESI/MS and TLC-DART/MS analyses. Reproduced with permission from Camag (TLC-Interface pictures) and from [61] (DESI and DART schemes).

\subsubsection{TLC-MS Interface}

The TLC-MS interface in the upgraded semi-automatic version has been available from CAMAG since the middle of 2009. Analytes adsorbed after development on the stationary phase of the TLC plate are cut together with a sorbent using cutting edges, eluted through a filter and transferred directly into a mass spectrometer. Precise elution is possible due to the laser-light enabling exact positioning of the elution head onto the zone of interest [60]. This type of hyphenation offers new possibilities for TLC which can become competitive with HPLC technique. According to the papers published during the last 5 years, direct TLC-MS connection has been successfully applied in analysis of food supplements, pharmaceuticals as well as water pollutants [12,15,64,65]. A continuous increase in the number of publications on the TLC-MS analysis of plant extracts and single plant components has also 
been observed, conducted both in the normal as well as in the reversed phase mode [66-69]. The TLC-MS interface is very useful in identification of biologically active compounds detected by TLC-DB methods. It is convenient to run the analyzed mixture in several replications (at least two) on the same TLC plate which, after development, can be cut along the tracks. Then, one track is left for UV and MS analysis and the others can be subjected to biological detection. In this way MS spectra can be acquired only for the compounds possessing biological activity. Such a solution was applied using TLC-DB assay against Aliivibrio fischeri strain in analysis of several anthocyanins in juice, pomace, wine and berry extracts $[12,15]$. A similar solution was proposed much earlier by Hostettmann and co-workers: the half of the plate with separated Swertia calycina (Gentianaceae) extract was immersed in suspension of fungi-Cladosporium cucumerinum-while the second, duplicated half of the plate was subjected to MS analysis [40].

\subsubsection{The DART System}

The first publication as well as the patent on DART-MS appeared in 2005 [70]. This new ion source was developed for the analysis of materials in open air under ambient conditions. Ionization is performed by reaction of electronic excited-state species of helium or vibronic-excited state species of nitrogen with analytes. The constituents can be desorbed and ionized directly from surfaces such as concrete, asphalt, glass, skin, currency, business cards, drugs, clothing, leaves, spices, fruits, and vegetables. Soon, it was proven that DART can be used to desorb and ionize samples from TLC plates [60,71]. The method has advantages over DESI-less damage of the plate and lack of liquid spreading effects which are connected with electrospray. The DART analysis is performed directly from (HP)TLC plates and MS results are obtained at once. There are early examples of using TLC-DART-MS for the separation and identification of plant consituents such as curcumin in extracts of Curcuma longa (Zingiberaceae) [72] and coumarins, alkaloids and lignans in medicinal plants [73].

\section{Other TLC-DB Possibilities}

The term bioautography is used predominantly when antimicrobial or antifungal properties of the analytes are measured on (HP)TLC plates. However, it can be also based on other, biological effects, e.g., antioxidant, enzymatic, antiestrogenic, or antimutagenic [6,10,11]. The most common are TLC-DPPH tests for detection of antioxidant activity of tested samples [74]. Bioautography assays concerning investigation of enzymatic activity are predominantly focused on inhibition of acetylcholinesterase, butyrylcholinesterase, $\alpha$ - and $\beta$ - glucosidases or xanthine oxidase [11]. TLC-DB yeast estrogen screen test (YES) is used for the measurement of estrogenic activity [75]. The application of several TLC-bioautography tests in parallel linked to chemical/spectroscopic methods provides complete information for either bioactivity or the structure of the target compounds. In many cases semi-quantitative results can be achieved $[6,36]$.

\section{Acknowledgments}

The authors are grateful to Gy. Horváth as well as to Á.M. Móricz, who was partially supported by OTKA grant PD83487 and by the Bolyai grant. 


\section{Author Contributions}

Irena. M. Choma and Wioleta Jesionek conceived and designed the experiments; Wioleta Jesionek performed the experiments; Irena. M. Choma and Wioleta Jesionek analyzed the data, wrote and revised the manuscript.

\section{Conflicts of Interest}

The authors declare no conflict of interest.

\section{References}

1. Cody, V.; Middleton, E.; Harborne, J.B. Plant Flavonoids in Biology and Medicine-Biochemical, Pharmacological, and Structure-Activity Relationships; Liss, A.R., Ed.; John Wiley \& Sons Inc: New York, NY, USA, 1986.

2. Langseth, L. Oxidants, Antioxidants and Disease Prevention; International Life Sciences Institute Europe Press: Brussels, Belgium, 1995.

3. The European Parliament and the Council. A second programme of Community action in the field of health (2008-13). Decision No 1350/2007/EC. Available online: http://eur-lex.europa.eu/legalcontent/EN/ALL/?uri=CELEX:32007D1350 (accessed on 21 November 2007).

4. The European Commission. Communication From The Commission On A Community Strategy against Antimicrobial Resistance (COM (2001) 333 final, volume I). Available online: http://europa.eu/legislation_summaries/public_health/threats_to_health/c11568_en.htm (accessed on 11 May 2015).

5. Barrett, J.F.; Davey, P.G.; McEwen, S.A.; O’Brien, T.F.; Levy, S.B.; Boston, M.A. Antibiotic Resistance: Synthesis of Recommendations by Expert Policy Groups; World Health Organization: Boston, MA, USA, 2001.

6. Choma, I.M.; Jesionek, W. Effects-Directed Biological Detection: Bioautography. In Instrumental Thin-Layer Chromatography; Elsevier: Amsterdam, The Netherlands, 2014.

7. Brack, W.; Ulrich, N.; Bataineh, M. Separation techniques in effect-directed analysis. In Effect-Directed Analysis of Complex Environmental Contamination; Springer-Verlag: Berlin/Heidelberg, Germany, 2011.

8. Brack, W. Effect-directed analysis in ecotoxicology. In Encyclopedia of Aquatic Ecotoxicology; Springer: Dordrecht, The Netherlands, 2013.

9. Hecker, M.; Hollert, H. Effect-directed analysis (EDA) in aquatic ecotoxicology: State of the art and future challenges. Environ. Sci. Pollut. Res. 2009, 16, 607-613.

10. Choma, I.; Grzelak, E.M. Bioautography detection in thin-layer chromatography. J. Chromatogr. A 2011, 1218, 2684-2691.

11. Marston, A. Thin-layer chromatography with biological detection in phytochemistry. J. Chromatogr. A 2011, 1218, 2676-2683.

12. Cretu, G.C.; Morlock, G.E. Analysis of anthocyanins in powdered berry extracts by planar chromatography linked with bioassay and mass spectrometry. Food Chem. 2014, 146, 104-112. 
13. Jesionek, W.; Choma, I.M.; Majer-Dziedzic, B.; Malinowska, I. Screening bacterial and radical scavenging properties of chosen plant extracts using thin-layer chromatography-direct bioautography. J. Liq. Chrom. Relat. Tech. 2014, 37, 2882-2891.

14. Jesionek, W.; Grzelak, E.M.; Majer-Dziedzic, B.; Choma, I.M. Thin-layer chromatography-Direct bioautography for the screening of antimicrobial properties of plant extracts. J. Planar Chromatogr. 2013, 26, 109-113.

15. Krüger, S.; Urmann, O.; Morlock, G.E. Development of a planar chromatographic method for quantitation of anthocyanes in pomace, feed, juice and wine. J. Chromatogr. A 2013, 1289, 105-118.

16. Morlock, G.E.; Schwack, W. Hyphenations in planar chromatography. J. Chromatogr. A 2010, 1217, 6600-6609.

17. Móricz, A.M.; Otta, K.H.; Ott, P.G.; Tyihák, E. Separation and detection of aflatoxins using overpressured-layer chromatography and bioautography. J. Planar Chromatogr. 2003, 16, 417-420.

18. Móricz, Á.M.; Szarka, S.; Ott, P.G.; Héthelyi, É.B.; Szóke, É.; Tyihak, E. Seperation and identification of antibacterial chamomile components using OPLC, bioautography and GC-MS. Med. Chem. 2012, 8, 85-94.

19. Grzelak, E.M.; Majer-Dziedzic, B.; Choma, I.M. Development of a novel direct bioautographythin-layer chromatography test: optimization of growth condition for Gram-negative bacteria, Escherichia coli. J. AOAC Int. 2011, 94, 1569-1572.

20. Grzelak, E.M.; Majer-Dziedzic, B.; Choma, I.M. Development of a novel direct bioautographythin-layer chromatography test: optimization of growth conditions for gram-positive bacteria, Bacillus subtilis. J. AOAC Int. 2013, 96, 386-391.

21. Grzelak, E.M.; Jesionek, W.; Majer-Dziedzic, B.; Choma, I.M. Applications of novel direct bioautography tests for analysis of antimicrobials: A review. J. AOAC Int. 2013, 96, 1167-1174.

22. Choma, I.M.; Grzelak, E.M.; Majer-Dziedzic, B. Comparison of deproteinization methods used before TLC-DB and HPLC analysis of flumequine residues in milk. Med. Chem. 2012, 8, 95-101.

23. Gałan, A.; Jesionek, W.; Majer-Dziedzic, B.; Lubicki, Ł.; Choma, I.M. Investigation of different extraction methods on the content of main components in Coffea arabica L. extracts. J. Planar Chromatogr. 2015, 28, 178-183.

24. Horváth, G.; Jámbor, N.; Végh, A.; Böszörményi, A.; Lemberkovics, É.; Héthelyi, É.; Kovács, K.; Kocsis, B. Antimicrobial activity of essential oils: The possibilities of TLC-bioautography. Flavour Fragr. J. 2010, 25, 178-182.

25. Horváth, G.; Szabó, L.G.; Lemberkovics, É.; Botz, L.; Kocsis, B. Characterization and TLCbioautographic detection of essential oils from some Thymus taxa. Determination of the activity of the oils and their components against plant pathogenic bacteria. J. Planar Chromatogr. 2004, 17, 300-304.

26. Shai, L.J.; McGaw, L.J.; Eloff, J.N. Extracts of the leaves and twigs of the threatened tree Curtisia dentata (Cornaceae) are more active against Candida albicans and other microorganisms than the stem bark extract. Afr. J. Bot. 2009, 75, 363-366.

27. Suleiman, M.M.; McGaw, L.J.; Naidoo, V.; Eloff, J.N. Detection of antimicrobial compounds by bioautography of different extracts of leaves of selected South African tree species. Afr. J. Trad. CAM 2010, 7, 64-71. 
28. Molnár, V.; Billes, F.; Tyihák, E.; Ott, P.G. Bioautographic detection of antimicrobial compounds in the edible shiitake mushroom. J. Planar Chromatogr. 2008, 21, 423-426.

29. Horváth, G.; Kocsis, B.; Lemberkovics, É.; Böszörményi, A.; Ott, P.G.; Móricz, Á. Detection of antibacterial activity of essential oil components by TLC-bioautography using luminescent bacteria. J. Planar Chromatogr. 2013, 26, 114-118.

30. Verbitski, S.M.; Gourdin, G.T.; Ikenouye, L.M.; McChesney, D.J. Detection of Actaea racemosa adulteration by thin-layer chromatography and combined thin-layer chromatographybioluminescence. J. AOAC Int. 2008, 91, 268-275.

31. Baumgartner, V.; Schwack, W. Enhanced quantitative evaluation of the HPTLC-bioluminescence detection. J. Liq. Chromatogr. Relat. Technol. 2010, 33, 980-995.

32. Móricz, Á.M.; Szarka, S.; Ott, P.G.; Kertesy, D.; Héthelyi, É.; Szőke, É.; Tyihák, E. Application of direct bioautography and SPME-GC-MS for the study of antibacterial Chamomile ingredients. J. Planar Chromatogr. 2012, 25, 220-224.

33. Verbitski, S.M.; Hickey, S.; Gourdin, G.T.; Ikenouye, L.M. Bioluminex: An effective yet simple tool for screening mixtures. CBS CAMAG Bibliogr. Serv. 2007, 99, 11-13.

34. Horváth, G.; Acs, K.; Kocsis, B. TLC-direct bioautography for determination of antibacterial activity of Artemisia adamsii essential oil. J. AOAC Int. 2013, 96, 1209-1213.

35. Choma, I.M.; Kowalski, C.; Lodkowski, R.; Burmańczuk, A.; Komaniecka, I. TLC-DB as an alternative to the HPLC method in the determination of cefacetril residues in cow's milk. J. Liq. Chrom. Relat. Tech. 2008, 31, 1903-1912.

36. Choma, I.M.; Choma, A.; Komaniecka, I.; Pilorz, K.; Staszczuk, K. Semiquantitative estimation of enrofloxacin and ciprofloxacin by thin-layer chromatography-direct bioautography. J. Liq. Chromatogr. Relat. Technol. 2004, 27, 2071-2085.

37. Tyihák, E.; Móricz, Á.M.; Ott, P.G. Use of the BioArena system for indirect detection of endogenous ozone in spots after TLC or OPLC separation. J. Planar Chromatogr. 2008, 21, 77-82.

38. Tyihák, E.G.; Móricz, Á.M.; Ott, P.G.; Kátay, G.; Király-Véghely, Z. The potential of BioArena in the study of the formaldehydome. J. Planar Chromatogr. 2005, 18, 67-72.

39. Homans, A.L.; Fusch, A. Direct bioautography on thin-layer chromatograms as a method for detecting fungitoxic substances. J. Chromatogr. A 1970, 51, 327-329.

40. Rodriguez, S.; Wolfender, J.-L.; Hakizamungu, E.; Hostettmann, K. An antifungal naphthoquinone, xanthones and secoiridoids from Swertia calycina. Planta Med. 1995, 61, 362-364.

41. Queiroz, E.F.; Ioset, J.-R.; Ndjoko, K.; Guntern, A.; Foggin, C.M.; Hostettmann, K. On-line identification of the bioactive compounds from Blumea gariepina by HPLC-UV-MS and HPLCUV-NMR, combined with HPLC-micro-fractionation. Phytochem. Anal. 2005, 16, 166-174.

42. Queiroz, E.F.; Wolfender, J.-L.; Atindehou, K.K.; Traore, D.; Hostettmann, K. On-line identification of the antifungal constituents of Erythrina vogelii by liquid chromatography with tandem mass spectrometry, ultraviolet absorbance detection and nuclear magnetic resonance spectrometry combined with liquid chromatographic micro-fractionation. J. Chromatogr. A 2002, 974, 123-134.

43. Gafner, S.; Wolfender, J.-L.; Nianga, M.; Stoeckli-Evans, H.; Hostetmann, K. Antifungal and antibacterial naphthoquinones from Newbouldia laevis roots. Phytochemistry 1996, 42, 1315-1320.

44. Tan, R.X.; Wolfender, J.-L.; Ma, W.G.; Zhang, L.X.; Hostetmann, K. Secoiridoids and antifungal aromatic acids from Gentiana algida. Phytochemistry 1996, 41, 111-116. 
45. Tan, R.X.; Wolfender, J.-L.; Zhang, L.X.; Ma, W.G.; Fuzzati, N.; Marston, A.; Hostettmann, K. Acyl secoiridoids and antifungal constituents from Gentiana macrophylla. Phytochemistry 1996, 42, 1305-1313.

46. Zhao, W.; Wolfender, J.-L.; Hostettmann, K.; Xu, R.; Qin, G. Antifungal alkaloids and limonoids derivatives from Dictamnus dasycarpus. Phytochemistry 1998, 47, 7-11.

47. Meazza, G.; Dayan, F.E.; Wedge, D.E. Activity o quinones on Colletotrichum species. J. Agric. Food Chem. 2003, 51, 3824-3828.

48. Altintas, A.; Tabanca, N.; Tyihák, E.; Ott, P.G.; Móricz, A.M.; Mincsovics, E.; Wedge, D.E. Characterization of volatile constituents from Origanum onites and their antifungal and antibacterial activity. J. AOAC Int. 2013, 96, 1200-1208.

49. Demirci, B.; Baser, K.H.C.; Tabanca, N.; Wedge, D.E. Characterization of volatile constituents of Haplopappus greenei and studies on the antifungal activity against phytopathogens. J. Agric. Food Chem. 2006, 54, 3146-3150.

50. Tabanca, N.; Demirci, B.; Crockett, S.L.; Baser, K.H.C.; Wedge, D.E. Chemical composition and antifungal activity of Arnica longifolia, Aster hesperius and Chrysothamnus nauseosus essential oils. J. Agric. Food Chem. 2007, 55, 8430-8435.

51. Wedge, D.E.; Klun, J.A.; Tabanca, N.; Demirci, B.; Ozek, T.; Baser, K.H.C.; Liu, Z.; Zhang, S.; Cantrell, C.L.; Zhang, J. Bioactivity-guided fractionation and GC/MS fingerprinting of Angelica sinensis and Angelica archangelica root components for antifungal and mosquito deterrent activity. J. Agric. Food Chem. 2009, 57, 464-470.

52. Navickiene, H.M.D.; Alécio, A.C.; Kato, M.J.; Cavalheiro, A.J.; Furlan, M. Antifungal amides from Piper hispidum and Piper tuberculatum. Phytochemistry 2000, 55, 621-626.

53. Móricz, Á.M.; Tyihák, E.; Ott, P.G. Usefulness of transgenic luminescent bacteria in direct bioautographic investigation of Chamomile extracts. J. Planar Chromatogr. 2010, 23, 180-183.

54. Jesionek, W.; Móricz, Á.M.; Alberti, Á.; Ott, P.G.; Kocsis, B.; Horváth, G.; Choma, I.M. TLC-DB as a bio-assay guided method for investigation of antibacterial compounds in Hypericum perforatum L. J AOAC Int. 2015, in press.

55. Móricz, Á.M.; Fornal, E.; Jesionek, W.; Majer-Dziedzic, B.; Choma, I.M. Effect-directed isolation and identification of antibacterial Chelidonium majus L. alkaloids. Chromatographia 2015, 78, 707-716.

56. Móricz, Á.M.; Ott, P.G.; Alberti, Á.; Böszörményi, A.; Lemberkovics, É.; Szőke, É.; Kéry, Á.; Mincsovics, E. Applicability of preparative overpressured layer chromatography and direct bioautography in search of antibacterial chamomile compounds. J. AOAC Int. 2013, 96, 1214-1221.

57. Móricz, A.M.; Ott, P.G.; Böszörményi, A.; Lemberkovics, É.; Mincsovics, E.; Tyihák, E. Bioassayguided isolation and identification of antimicrobial compounds from thyme essential oil by means of overpressured layer chromatography, bioautography and GC-MS. Chromatographia 2012, 75, 991-999.

58. Mincovics, E.; Ott, P.G.; Alberti, Á.; Böszörményi, A.; Héthelyi, É.B.; Szőke, É.; Kéry, Á.; Lemberkovics, É.; Móricz, Á. In-situ clean-up and OPLC fractionation of chamomile flower extract to search active components by bioautography. J. Planar Chromatogr. 2013, 26, 172-179.

59. Dzido, T.; Lopaciuk, E.; Płochacz, P.W.; Chomicki, A.; Zembrzycka, M.; Frank, H. Equipment and preliminary results for orthogonal pressurized planar electrochromatography. J. Chromatogr. A 2014, 1334, 149-155. 
60. Morlock, G.E.; Schwack, W. Coupling of planar chromatography to mass spectrometry. Trends Anal. Chem. 2010, 29, 1157-1171.

61. Cooks, R.G.; Ouyang, R.; Takats, Z.; Wiseman, J.M. Ambient Mass Spectrometry. Science 2006, 311, 1566-1570.

62. Van Berkel, G.J.; Ford, M.J.; Deibel, M.A. Thin-layer chromatography and mass spectrometry coupled using desorption electrospray ionization. Anal. Chem. 2005, 77, 1207-1215.

63. Morlock, G.E.; Ueda, Y. New coupling of planar chromatography with direct analysis in real time mass spectrometry. J. Chromatogr. A 2007, 1143, 243-251.

64. Klöppel, A.; Grasse, W.; Brümmer, F.; Morlock, G.E. HPTLC coupled with bioluminescence and mass spectrometry for bioactivity-based analysis of secondary metabolites in marine sponges. J. Planar Chromatogr. 2008, 21, 431-436.

65. Morlock, G.E.; Schuele, L.; Grashorn, S. Development of a quantitative high-performance thinlayer chtomatographic method for sucralose in sewage effluent, surface water and drinking water. J. Chromatogr. A 2011, 1218, 2745-2753.

66. Naumoska, K.; Simonovska, B.; Albreht, A.; Vovk, I. TLC and TLC-MS screening of ursolic, oleanolic and betulinic acids in plant extracts. J. Planar Chromatogr. 2013, 26, 125-131.

67. Naumoska, K.; Vovk, I. Analysis of triterpenoids and phytosterols in vegetables by thin-layer chromatography coupled to tandem mass spectrometry. J. Chromatogr. A 2015, 1381, 229-238.

68. Smrke, S.; Vovk, I. Comprehensive thin-layer chromatography mass spectrometry of flavanols from Juniperus communis L. and Punica granatum L. J. Chromatogr. A 2013, 1289, 119-126.

69. Sajewicz, M.; Staszek, D.; Natic, M.; Waksmundzka-Hajnos, M.; Kowalska, T. TLC-MS versus TLC-LC-MS fingerprints of herbal extracts. Part III. Application of the reversed-phase liquid chromatography systems with C18 stationary phase. J. Chromatogr. Sci. 2011, 49, 560-567.

70. Cody, R.B.; Laramée, J.A. Atmospheric Pressure Ion Source. US Patent Number 6,949,741, 27 September 2005.

71. Morlock, G.E.; Schwack, W. Determination of isopropylthioxanthone (ITX) in milk, yoghurt and fat by HPTLC-FLD, HPTLC-ESI/MS and HPTLC-DART/MS. Anal. Bioanal. Chem. 2006, 385, 586-595.

72. Kim, H.J.; Young, P.J. Direct znalysis of curcumin in turmeric by DART-MS. Phytochem. Anal. 2009, 20, 372-377.

73. Kim, H.J.; Jee, E.H.; Ahn, K.S.; Choi, H.S.; Jang, Y.P. Identification of marker compounds in herbal drugs on TLC with DART-MS. Arch. Pharm. Res. 2010, 33, 1355-1359.

74. Cieśla, Ł.; Kryszeń, J.; Stochmal, A.; Oleszek, W.; Waksmundzka-Hajnos, M. Approach to develop a standardized TLC-DPPH• test for assessing free radical scavenging properties of selected phenolic compounds. J. Pharm. Biomed. Anal. 2012, 70, 126-135.

75. Morlock, G.E.; Klingelhöfer, I. Liquid chromatography-bioassay-mass spectrometry for profiling of physiologically active food. Anal. Chem. 2014, 86, 8289-8295.

(C) 2015 by the authors; licensee MDPI, Basel, Switzerland. This article is an open access article distributed under the terms and conditions of the Creative Commons Attribution license (http://creativecommons.org/licenses/by/4.0/). 